\title{
Virtual Supply Chain Management System: A decision support system using discrete event simulation
}

\author{
S. Umeda ${ }^{*}$ and A. Jones \\ National Institute of Standards and Technology \\ MET 220 Rm A127 NIST Gaithersburg MD 20899-001 USA \\ *) currently Musashi University, 1-26 Toyotama-kami Nerima Tokyo 176 Japan \\ Tel: +81 35984 3837, Fax: +81 33991 1198, Shigekiạcc.musashi.ac.jp
}

\begin{abstract}
This paper proposes an integration test-bed system for supply chain management, which forms the foundation for the construction of a valued manufacturing chain. The test-bed especially focuses on Production and Operations Management (POM) issues within the chained firms. The characteristics of this system are 1) an enterprise integration model and architecture which represent business and information process in supply chain, 2) a hierarchical simulation system to support production management in supply chain, 3) the communication data interface between the simulation and the suppliers companies, and 4) Decision support system based on statistical methods. This paper introduces the system's concept and architecture through an application example.
\end{abstract}

Keywords

Supply chain management, Business modeling, System integration, Decision support system, Simulation

\section{INTRODUCITON}

Supply Chain Management (SCM) is currently one of the areas, which have received a great deal of attention in business community. In the United States, the logistics costs is said to be $30 \%$ of cost of goods sold in average U.S. manufacturing firms (Ballou, 1992). The Yankee Group, a Boston-based consulting firm, also points to a study of 1,000 European firms that shows leading companies operating with 36 percent lower logistics costs than the average. Supply-chain cost is estimated at 10 percent of the revenues of most companies, that they are nearly 4 percent increase in net profit margin (Davis,1995). 
The origin of supply chain analysis is the Quick Response manufacturing (QR) concept in apparel industry from raw material to consumer. After that study, industry has changed to adopt the UPC code by the grocery industry and electronic data interchange (EDI) standards. Retailers began to install POS systems to transfer sales information rapidly to distributors and manufacturer. This work was succeeded in the Efficient Consumer Response (ECR) (Kurt salmon Assoc., 1993), and Continuous Replenishment (CR) in grocery chain (ECR, 1994). Point-ofpurchase transactions are forwarded by computer to the manufacturer, allowing them to keep the retailer replenished and balanced just-in-time (Garry,1994).

The common goals of the above concepts are "Shorten total lead time" and "Cost down in total operations". Companies must own information sharing mechanism to synchronize the operation flows with information flows in supply chain, which becomes more complex than the case of single company. The companies also requires to redesign their management operations and information processing systems towards the "Enterprise Integration". Such re-engineering operations will require pre-estimation facilities to change management and the cooperative works among them.

This paper proposes a simulation-based integration test-bed system supporting to design such multiple supply chain management operations. This system can simulate not only physical material handling but also production management behaviors and data communication transactions among suppliers. The system will also give a solution to design the database systems and data communication interfaces among firms in the chain.

\section{System Architecture for Virtual Supply Chain Management}

The system is composed of the following sub-systems (Figure. 1):

- Hierarchical supply chain simulation system

- Supply-chain management communication server

- Suppliers management decision support system

The hierarchical simulation system simulates activities according as the supply chain management layers: These are "Chain", "Factory", and "Cell", respectively. The "Chain" level simulation scopes a business process simulation. so-called "Virtual Suppliers Manager (VSM)". The "Factory" level simulation scopes individual factory in the chain. These suppliers include factories, warehouses, distributors, and global area transportors. The "Cell" level simulation covers the activities within each process of the factory.

The communication server owns three modules to communicate the tactical data among the suppliers. It provides the data exchange facilities to transfer the data with the decision support system to generate ordering data as necessary. The WEB system driver is a subsystem that exchanges data among the suppliers. The handled data covers production data from supplier's factories, distribution data from retailers, and demand data from retailers and customers. This module also 
publishes the management data for production and distribution to suppliers, when it is needed. The production data driver collects production and distribution data and processes them. Some of them are sent to both the simulation system and the decision support system. The demand data driver collects demand data from the distributors and customers, and process them. The processed data is sent to both simulation system and decision support system.

The suppliers management decision support system provides production managers with management information by using "Suppliers Management Knowledge Data Base" and "Data Analyzer". The former is a set of rules to manage suppliers operations, and the later is a set of routines of statistical data analysis or mathematical programming.

The individual system uses the data information models to communicate each other. The models used here identify all of the business activities and relationships among chained suppliers (Umeda, 1996,1997).

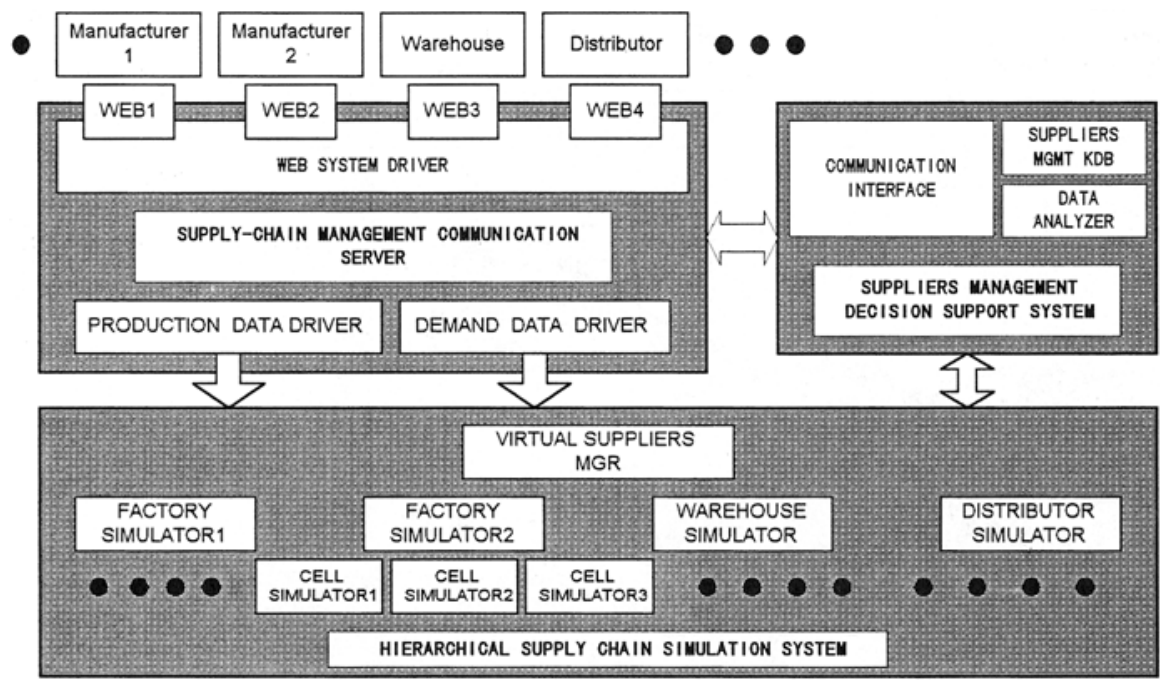

Figure.1 System architecture

\section{Supply chain simulation system}

\subsection{Hierarchical structure of simulation}

The tasks of the system is to simulate:

- Ordering processes to individual suppliers in the chain

- Individual suppliers (factories) activities according as the orders in the chain

- Transactions occurred at manufacturing processes in the chain.

The simulation shows all of the activities in the chain process and behaviors controlled by the production orders or daily schedules. The simulation kernel is 
composed of three layers hierarchical models according as the operational level. These layers are individually "Chain", "Factory", and "Cell".

The "Chain" layer simulation represents activities of production management process, such as operations ordering and inventory management. The suppliers operations are controlled by a specific business process simulator, which is called as "Virtual Suppliers Manager (VSM)". VSM simulates business processes of production preparations, production, and delivery. The basic ordering operations are classified into "PUSH" mode and "PULL" mode. The details of behavior of VSM will be described in the next section.

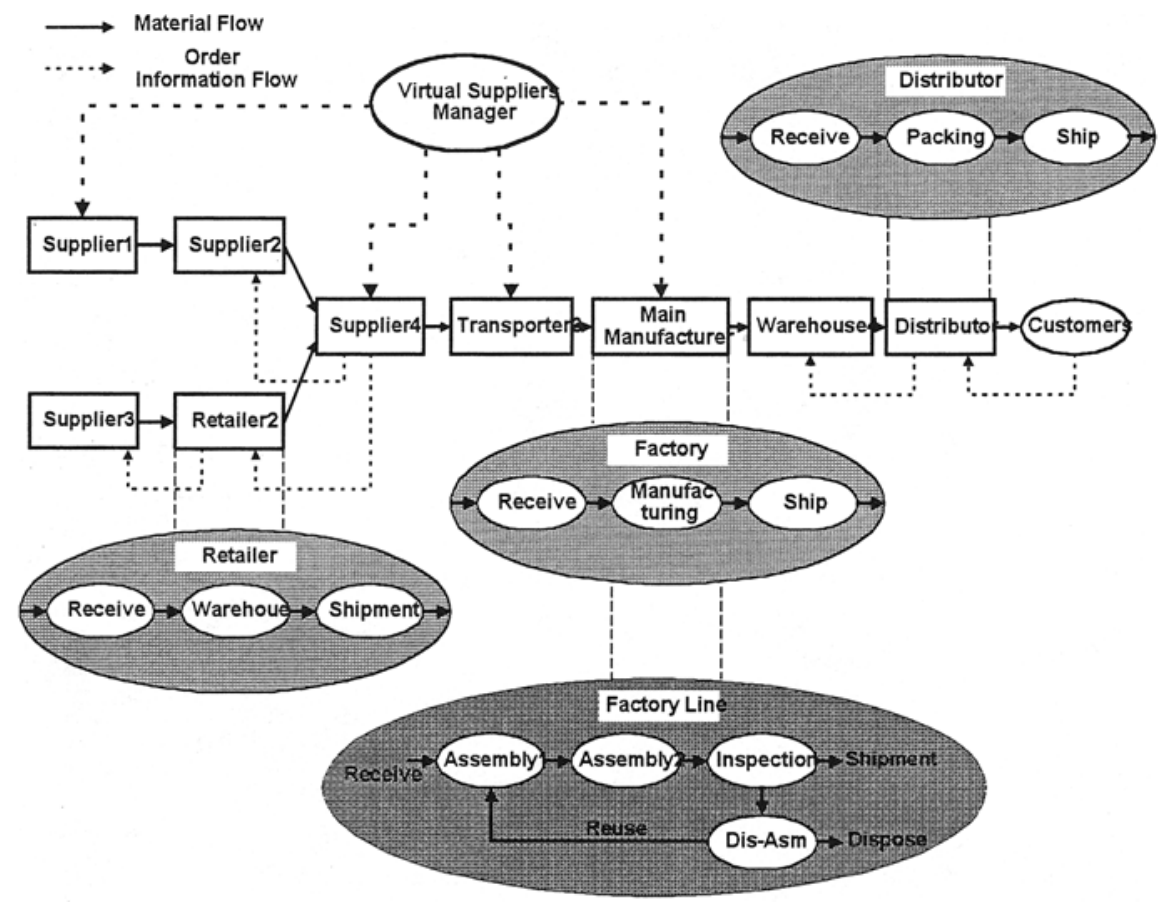

\section{Fig.2 Hierarchical supply chain simulation}

The "Factory" layer simulation shows factories activities, such as machining processes, transportation, and buffering process. Individual simulation exchanges the transactions data with its upper and lower layers. Factories include, at least, more than one material processing systems (manufacturing line). The general feature is similar to the traditional manufacturing line simulation. The difference with them is that the activities at several particular processes (manufacturing, 
shipment, transport, and material entry) are controlled by the orders from the VSM.

The "Cell" layer's simulations make up the lowest level. These are usually control logic simulations. The input is the physical transaction control rules of a particular machine or resource, such as NC machines or robot control program. The output is, for example, machine performance or part quality.

\subsection{Virtual Suppliers Manager}

Virtual Suppliers Manager (VSM) is a virtual organization to control suppliers in the chain. While another layers' simulations present physical activities in suppliers, VSM is a business process simulation of the ordering activities to the factories in the chain. It receives demand orders from distributors or customers, and gives orders to supplier's factories. It also includes simulations of global transportation, material purchasing, products shipment.

VSM is directly linked with the particular suppliers that work in "PUSH" mode. VSM uses inventory data of input/output parts in the suppliers, demands data in phased time, and BOM tables representing parts construction. VSM produces the operation orders to the individual suppliers' factories, warehouses, transporter, and distributors. This mechanism is so-called schedule-driven method. First of all, VSM predicts demand volume in the next phased term by using the past log data of demand and production, and builds "Master Production Schedule" (MPS). The second step is the calculation of the each part volume required in individual factory by using part explosion technique. The last step is the ordering processes, which give the production orders to individual supplier. VSM plays a role of prime contractor such "PUSH" system in the suppliers' chain.

Some of suppliers in the chain define the individual replenishment points on inventories, and independently make orders to their up-stream suppliers. The upstream suppliers which received the orders work as necessary. This "PULL" system is the contrast with the above "PUSH" system. A typical example of "PULL" system is a Kanban system.

VSM provides "hybrid PUSH-PULL" system environment to represent manufacturing logistics in supply chain. This scenario is a combination of "PUSH" and "PULL" methods in the chain. This facility give a good solution to the "PULL factory selection problem", which is often difficult choice at practical operations planning. The solution gives impacts not only on material flow control but also on information processing between the prime contractor and suppliers. The examples are:

- Suppose that all of factories in the chain uses common database for purchase ordering process, what impacts occur on total lead time in the chain?

- Suppose that two processes of internal and external production planning are linked together, what impacts occur on the total productivity in the chain?

- Suppose that all factories and distributors works on PULL-mode, all of planning processes will be extremely simplified. While, all factories always 
keep balanced inventory, and require distributed inventory management system. Which is better?

\section{Towards Enterprise Integration}

Solutions to such above problems require numerous simulation runs. Simulation will produce a huge volume of output data. We will face to both simulation experiment design problems and output data analysis problems. The solutions to practical issues will be typical multi-objective optimization problems. Furthermore, the data for simulation input is distributed among the suppliers. The output data will have to be sent to the distributed suppliers. The system integration will be needed to utilize them to produce concrete solutions for production management in the chain.

The design and optimization methods uses "Response Surface Model", which is one of generic methods of sensitivity analysis. We are also applying the "Taguchi methods" to select effective simulation parameters of simulation runs. In addition to using such optimization technologies, we must also utilize specific heuristics knowledge of operations management in supply chain. Such knowledge will help to choose proper parameters to analyze systems. The problems will include such as the following examples.

- Suppose that all of factories in the chain uses common database for purchase ordering process, what impacts occur on total lead time in the chain?

- Suppose that two processes of internal and external production planning are linked together, what impacts occur on the total productivity in the chain?

- Suppose that some particular suppliers work in PULL-mode, what impacts occur on the inventories in the chain?

Successful SCM also requires the sharing information facilities other than simulation and data analysis support. The current version of the communication server provides the transportation of the tactical data to manage supply chain. The objective of this information sharing facility is to perform synchronized manufacturing and logistics operations. Communication server includes three data driver sub-systems, as follows:

1. The Production Data Driver receives tactical operational data from suppliers and translates it to meet the format specifications of the target software applications (simulator and optimizer). Most of them are operations management application like partial modules of commercial ERP packages.

2. The Demand Data Driver receives demands data from retailers or distributors. The data is partially reformed to parameters of simulator and optimizer, and partially used to the demand prediction.

3. The Communication server provides the data access methods and utilities, which the above drivers use. This server is to provide both real time data transfer and batch data transfer among the companies in the chain. These include the input /output data of the simulation described the previous sections. 
At the first stage of implementation, we developed the simulation input data interface by using CGI (Common Gaterway Interface), and the simulation output data interface by using Java.

\section{Application examples}

The current version of the system demonstrates a case study of PC manufacturing supply chain. The chain is composed of parts factories (Keyboard, CDROM, SDRAM, Circuit board, and Main box), warehouses, and distribution center. The VSM generates production orders to send to individual suppliers by using BOM (Bills Of Materials) tables, and it send transportation orders to distributors to carry products to suppliers.

This industry is one of the typical examples that are composed of "hybrid PUSH-PULL" logistics supply chain. The dotted lines represent orders information flows. Several suppliers pull directly the products from the suppliers, but, if they so, they must keep minimum volume of inventories to some extent.

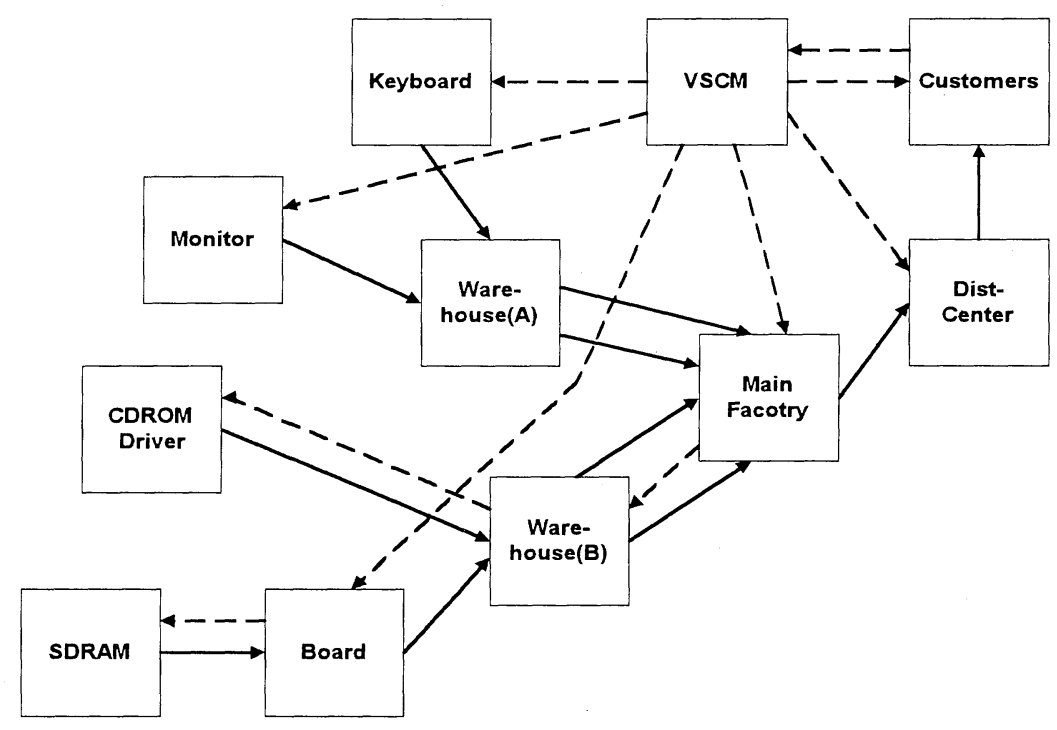

Fig.3 An example of supply chain system in PC manufacturing

We have applied, here, two examples for SCM planning problem. The first example is the total planning lead-time reduction problem. Companies tries to reduce planning lead-time, and the situation is the same as suppliers chain. If the chain members succeed in reducing planning lead-time respectively, the productivity and flexibility will raise up. In this experiment, simulation has found that $25 \%$ up of order fulfillment will be established if the planning lead-time was 
shorten to $50 \%$ of current level. The second one is the inventory planning problem at individual suppliers. Every suppliers must own the minimum inventories, because the demands are not constant. The volume of inventory depends on the variance of demand volumes. The demand variance is statistically represented as the standard deviation of order volumes in every planning phase. By the experiments of factorial design, we could find that every suppliers must keep inventories which volume is equivalent to 2 working shift time.

\section{Conclusion and Future research}

The prime problem of supply chain management is that customers' demand is always unpredictable. It is not saying that the statistical data analysis techniques enable to predict the long-term demand trends in some extend. This analysis is often useful to build the enterprise management strategy in the long term. While, we must consider the methodologies to be applicable to the problems in both tactical and operational time phases.

A key solution in the success of supply chains is to shorten the total business process lead-time by the synchronization of operations among multiple suppliers by using information technologies. The proposed framework will lead to integrated operations management, and customer satisfaction. The principle of this strategy is, what we call, "Quick response than the better prediction."

\section{REFERENCES}

Ballou,R.H. (1992) Business Logistics Management, Prentice-Hall, Englewood Cliff, NJ, $3^{\text {rd }}$ ed.

Davis (1995) "Sate of a New Art: Manufacturing and Trading Partners Learn as They Go." Manufacturing Systems

Kurt Salmon Associates, Inc. (1993) Efficient Consumer Response: Enhancing Consumer Value in the Grocery Industry. Food Marketing Institute

The ECR Performance Measures Operating Committee (1994) Performance Measurement, Applying Value Chain Analysis to the Grocery Industry. Joint Industry Project on Efficient Consumer Response

Garry, M. (1994) "Is There Life After CRP?" Progressive Grocer, September

Umeda, S. (1997) "A Reference Model for Manufacturing Enterprise System by using OMT method, ACM SIGGROUP Bulletin, 8, 1, 54-57.

Umeda, S. (1996) "An object-oriented system model for manufacturing enterprise information system", 395-400, Proc. of APMS, IFIP WG5.7. 